\title{
Differential Effects of Novel Dopamine Reuptake Inhibitors on Interference With Long-Term Social Memory in Mice
}

\author{
Judith Camats-Perna ${ }^{1 \dagger \neq}$, Predrag Kalaba ${ }^{2 \neq}$, Karl Ebner ${ }^{3}$, Simone B. Sartori ${ }^{3}$, \\ Harish Vuyyuru ${ }^{2}$, Nilima Y. Aher ${ }^{2}$, Vladimir Dragačević ${ }^{2}$, Nicolas Singewald ${ }^{3}$, \\ Mario Engelmann ${ }^{1,4 *}$ and Gert Lubec ${ }^{5}$
}

${ }^{1} A G$ Neuroendokrinologie und Verhalten, Institut für Biochemie und Zellbiologie, Otto-von-Guericke-Universität Magdeburg, Magdeburg, Germany, ${ }^{2}$ Department of Pharmaceutical Chemistry, Faculty of Life Sciences, University of Vienna, Vienna, Austria, ${ }^{3}$ Center for Molecular Biosciences Innsbruck (CMBI), Department of Pharmacology and Toxicology, Institute of Pharmacy, Leopold Franzens University Innsbruck, Innsbruck, Austria, ${ }^{4}$ Center for Behavioral Brain Sciences, Magdeburg, Germany, ${ }^{5}$ Department of Neuroproteomics, Paracelsus Medical University, Salzburg, Austria

OPEN ACCESS

Edited by:

James P. Curley,

University of Texas at Austin, United States

Reviewed by:

Sukwon Lee,

Korea Brain Research Institute,

South Korea

Regis Parmentier,

Centre National de la Recherche

Scientifique (CNRS), France

${ }^{*}$ Correspondence:

Mario Engelmann

mario.engelmann@med.ovgu.de

tPresent address:

Judith Camats-Perna,

Clem Jones Centre for Ageing

Dementia Research, Queensland

Brain Institute, The University of

Queensland, Brisbane,

QLD, Australia

FThese authors have contributed equally to this work

Received: 28 August 2018 Accepted: 13 March 2019 Published: 11 April 2019

Citation:

Camats-Perna J, Kalaba P, Ebner K, Sartori SB, Vuyyuru H, Aher NY,

Dragačević $V$, Singewald N,

Engelmann $M$ and Lubec $G$ (2019) Differential Effects of Novel Dopamine Reuptake Inhibitors on Interference With Long-Term Social Memory in Mice.

Front. Behav. Neurosci. 13:63. doi: 10.3389/fnbeh.2019.00063
In the laboratory, long-term social recognition memory (SRM) in mice is highly susceptible to proactive and retroactive interference. Here, we investigate the ability of novel designed dopamine (DA) re-uptake inhibitors (rac-CE-123 and S-CE-123) to block retroactive and proactive interference, respectively. Our data show that administration of rac-CE-123 30 min before learning blocks retroactive interference that has been experimentally induced at $3 \mathrm{~h}$, but not at $6 \mathrm{~h}$, post-learning. In contrast, S-CE-123 treatment 30 min before learning blocked the induction of retroactive interference at $6 \mathrm{~h}$, but not $3 \mathrm{~h}$, post-learning. Administration of S-CE-123 failed to interfere with proactive interference at both $3 \mathrm{~h}$ and $6 \mathrm{~h}$. Analysis of additional behavioral parameters collected during the memory task implies that the effects of the new DA re-uptake inhibitors on retroactive and proactive interference cannot easily be explained by non-specific effects on the animals' general social behavior. Furthermore, we assessed the mechanisms of action of drugs using intracerebral in vivo-microdialysis technique. The results revealed that administration of rac-CE-123 and S-CE-123 dosedependently increased DA release within the nucleus accumbens of freely behaving mice. Thus, the data from the present study suggests that the DA re-uptake inhibitors tested protect the consolidation of long-term social memory against interference for defined durations after learning. In addition, the data implies that DA signaling in distinct brain areas including the nucleus accumbens is involved in the consolidation of SRM in laboratory mice.

Keywords: cognitive enhancement, social recognition memory, retroactive interference, aggression social interaction, dopamine transport inhibitor, long-term memory

\section{INTRODUCTION}

Social recognition memory (SRM) is the ability to distinguish between familiar and unfamiliar conspecific individuals (Thor and Holloway, 1982; Steckler et al., 1998). More than 100 years ago, Müller and Pilzecker postulated that information acquired during learning require some time to become long lasting memories and coined for this process the term "consolidation." 
The same authors have introduced the concept of retroactive interference by determining that acquired information can be "displaced" by the amnesic effect of subsequent newly acquired information (Müller and Pilzecker, 1900). In contrast to retroactive interference, proactive interference is considered when the past learned event interferes with the acquisition/consolidation/retrieval of new information (Camats Perna and Engelmann, 2017).

Previous studies have shown that SRM is highly susceptible to manipulations aimed at producing retroactive and proactive interference (Dantzer et al., 1987; Engelmann, 2009). In the course of these studies, it was shown that the nature and timing of defined stimuli after and before learning, respectively, are the prominent factors to determine whether interference occurs. SRM experiments performed in mice demonstrated that after learning, retroactive interference could be observed up to $15 \mathrm{~h}$ and proactive interference can be observed up to $9 \mathrm{~h}$. After learning, protein synthesis required for consolidation of both memory traces seems first to collide, then to compete, and finally overwrite each other in a time-dependent manner. After $18 \mathrm{~h}$, both "memory traces" seem to dissociate and consolidate independently from each other (Engelmann, 2009).

The neuronal processing of stimuli acquired by defined sensory modalities may cause interference in SRM. Experiments investigating the basis for retroactive interference revealed that exposure to stimuli activating audition, taction, vision and olfaction up to $6 \mathrm{~h}$ after learning affect memory (Noack et al., 2010; Perna et al., 2015). It was also shown that stimuli which simultaneously activate different sensory modalities cause a robust interference when compared to stimuli that activate fewer sensory modalities: transient retrograde amnesia triggered by $1 \%$ isoflurane was able to block retroactive interference induced by an object stimulus, but had no effect when a conspecific stimulus animal was used to produce interference (Camats Perna and Engelmann, 2017). Thus, the manipulation of interference phenomena in SRM may both help to develop new pharmacological tools for the treatment of memory decline ("cognitive enhancers") and provide new insight in the neuronal networks involved in the consolidation of this type of memory.

Modafinil is a wake-promoting drug which is used to treat sleep apnea, narcolepsy and shift work sleep disorders (Battleday and Brem, 2015; Kristofova et al., 2018). Recently, the synthesis and test in different behavioral paradigms of modafinil analogue 5-((benzhydrylsulfinyl)methyl)-thiazole (CE-123; Kalaba et al., 2017; Nikiforuk et al., 2017) was reported. CE-123 was structurally modified by substituting the carboxyl-amide moiety of modafinil with a heterocycle thiazole group attached to position five which may provide a high metabolic stability of CE-123. In vitro the racemate of CE-123 (rac-CE-123) blocks the dopamine transporter (DAT) with high specificity and no adverse side effects (Kalaba et al., 2017).

Pharmacokinetic studies showed that rac-CE-123 penetrates the blood-brain barrier and reaches its site of action in the brain within $\sim 30$ min after intraperitoneal administration in rats. Intraperitoneal administration of rac-CE-123 into SpragueDawley rats enhanced the acquisition and retrieval of memory in spatial hole-board task (Kristofova et al., 2018). It improved working memory in the radial arm maze and seems to modulate also the DA receptor in vivo (Kristofova et al., 2018). Further, $S$-CE-123 has also proven to enhance the cognitive flexibility without triggering unnecessary impulsive responding (Nikiforuk et al., 2017).

The present study was designed to assess the impact of CE-123 on the phenomenon of memory interference in SRM. In addition to the racemate, we used $S$-CE-123. The social discrimination task was performed in mice, and two different time points after the 1 st sampling ( 3 and $6 \mathrm{~h}$ ) were selected to evaluate possible effects on retroactive or proactive interference during SRM consolidation. Further, additional parameters were monitored during the behavioral tests to allow a first identification of possible behavioral side effects of the treatment that might have affected the behavioral readout interpreted as "memory."

In addition, we used microdialysis to investigate the effects of a single systemic administration of rac-CE-123 and S-CE123 on extracellular DA levels in the mouse nucleus accumbens. Previous studies have shown that this brain area might be involved in the correct processing of short-term SRM in rats (Ploeger et al., 1991).

\section{MATERIALS AND METHODS}

\section{Animals and Housing Conditions}

For behavioral testing, adult male C57BL/6JOlaHsd mice (Harlan-Winkelmann, Borchen, Germany) with an age group of 9-16 weeks were used as experimental subjects. If not stated otherwise, they were housed in groups of five per cage (size: $20 \times 37 \times 15 \mathrm{~cm}$ ) for at least 1 week before starting the experiments under standard laboratory conditions (temperature $22 \pm 1{ }^{\circ} \mathrm{C}$, humidity $60 \pm 5 \%$ with a $12: 12 \mathrm{~h}$ light-dark cycle lights on: 07:00 h). Stimulus animals were C57BL/6JOlaHsd mice of both sexes with an age of 25-35 days. For microdialysis experiments, adult male C57BL/6J mice were used. These animals were kept under similar conditions and experiments starting at 08:00-08:30 h. All experimental manipulations were approved by the Committee on Animal Health and Care of the local governmental body (Regierungspräsidium, Halle, registered and approved: 42502-2-1365 UniMD; microdialysis procedures were approved by the Austrian Animal Experimentation Ethics Board; Bundesministerium für Wissenschaft Forschung und Wirtschaft, Kommission für Tierversuchsangelegenheiten) and performed in strict compliance with the EEC recommendations for the care and use of laboratory animals (2010/63/EU).

\section{Behavioral Procedure}

The social discrimination test performed has been described in detail in Engelmann et al. (2011). In brief, experimental subjects were separated $2 \mathrm{~h}$ before starting the session by transferring them to small cages with fresh bedding. The test procedure consisted of two sampling sessions ( $4 \mathrm{~min}$ each) and one choice session $(4 \mathrm{~min})$ performed in the adult's cage under dimmed lighting conditions (during the light phase, i.e., between 8:00 and 15:00 h). During the 1st sampling, a given stimulus animal was exposed to the experimental subject and the behavior of the 
A
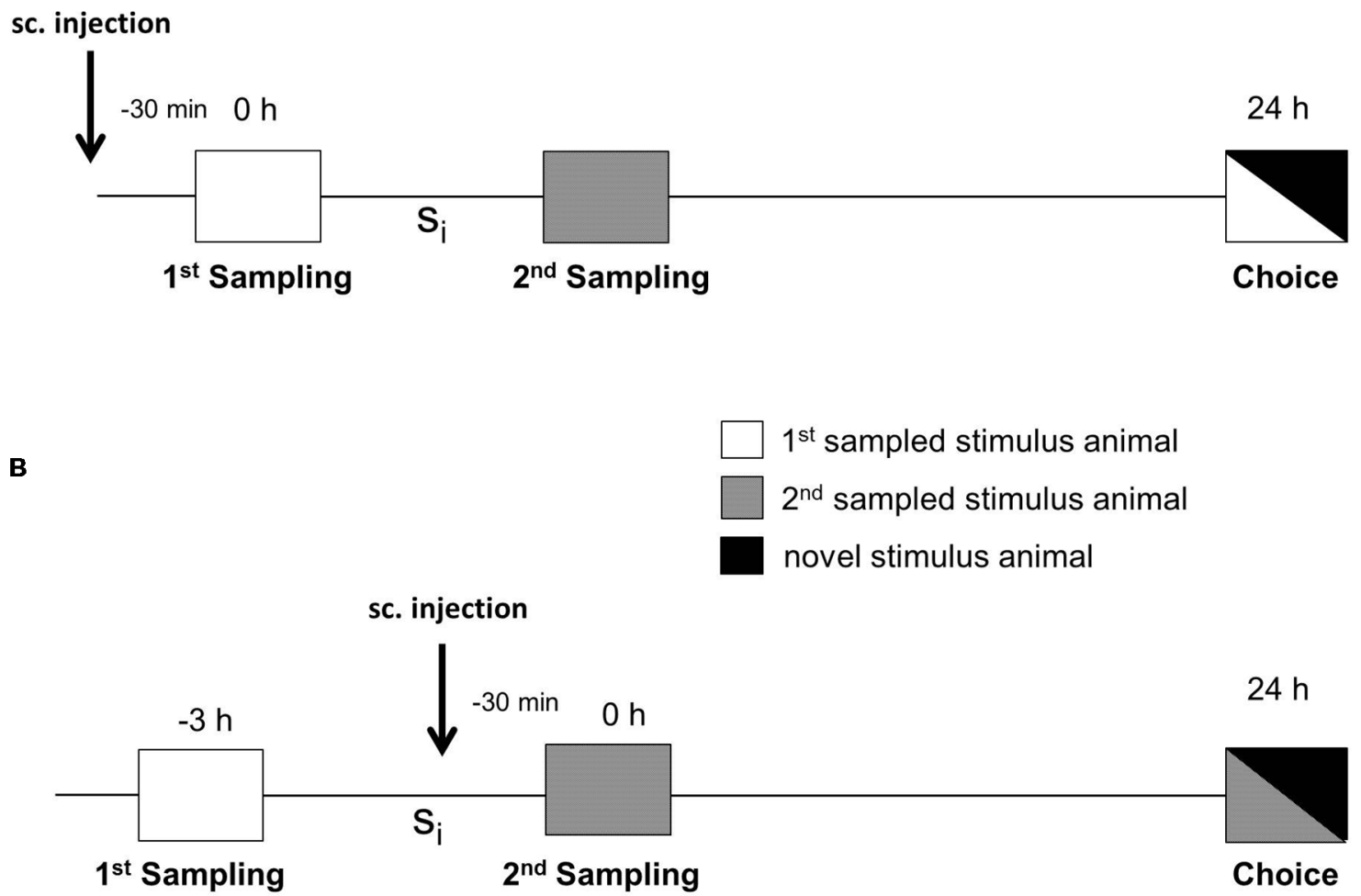

FIGURE 1 | Experimental protocol for testing the effects of the defined substances on interference in social recognition memory (SRM). (A) Subcutaneous (sc) injection was performed 30 min before the 1st sampling to measure the impact of administered substances on retroactive interference during choice.

(B) Subcutaneous injection was performed 30 min before the 2 nd sampling to measure the effect of administered compounds on proactive interference. The two samplings were separated by a defined sampling interval $\left(\mathrm{S}_{\mathrm{i}}\right)$. Choice took place either $24 \mathrm{~h}$ after the 1 st sampling, when testing retroactive interference (A), or $24 \mathrm{~h}$ after the 2nd sampling when testing proactive interference (B).

latter was monitored by pressing the pre-set key on a laptop by a trained observer unaware of the experimental subjects' treatment. The stimulus animal was then removed and kept individually in a new cage with food and water ad libitum. As illustrated in Figure 1, after a defined sampling interval $\left(S_{i}\right)$, a second, previously not encountered stimulus animal was presented for $4 \mathrm{~min}$ to the experimental subject during the 2 nd sampling session. To measure retroactive interference, during retrieval (choice), the stimulus animal encountered during the 1st sampling was presented to the experimental subject together with a novel stimulus animal $24 \mathrm{~h}$ after the 1 st sampling. To measure the proactive interference, during the choice session, the 2nd sampled stimulus animal was presented to the adult together with a novel stimulus animal. Significant longer investigation of the novel stimulus animal compared to the already encountered stimulus animal during choice was taken as evidence for an intact recognition memory (Thor and Holloway, 1982; Engelmann et al., 2011). Earlier studies revealed that the consolidation of long-term SRM corresponds to two phases of anisomycin sensitivity with a gap at $3 \mathrm{~h}$ after sampling (Richter et al., 2005). We used both an $S_{i}$ of $3 \mathrm{~h}$ (in the gap) and $6 \mathrm{~h}$ (after the gap) for our studies.

In addition to the investigation duration also the latency between the introduction of the stimulus animal in the experimental subject's cage and the first approach of the experimental subject towards the stimulus animal was monitored. Also, the duration of aggressive and sexual behavior of the experimental subject towards the given stimulus animal during the 1 st and 2 nd sampling was monitored.

\section{Drug Treatment}

The following drugs were used in the present study: rac-CE123 = 5-((benzhydrylsulfinyl)methyl)-thiazole (Kristofova et al., 2018) and S-CE-123 = S-5-((benzhydrylsulfinyl)methyl)thiazole (Nikiforuk et al., 2017). The dosage of the drugs and the time point of administration were selected according to previous studies in which it was shown that $10 \mathrm{mg}$ of the drugs per $\mathrm{kg}$ body weight administered $30 \mathrm{~min}$ before testing produces significant learning and memory effects without causing detectable undesired side effects in rats (Nikiforuk et al., 2017; Kristofova et al., 2018). The drugs were dissolved in 1\% DMSO and 3.3\% Tween 80 diluted in $0.9 \% \mathrm{NaCl}$. The solution contained $1 \mathrm{mg} / \mathrm{ml}$ and the dosage administered was $10 \mathrm{mg} / \mathrm{kg}$ body weight for all drugs. Vehicle contained the solvent (1\% DMSO and $3.3 \%$ Tween 80 diluted in $0.9 \% \mathrm{NaCl}$ ) only. The experiments were performed in a double-blind cross-over design. Thus, all animals received both vehicle and the given drug in a random order. The code was broken after the end of the 
behavioral experiments when the data was assigned to each treatment conditions and finally analyzed.

For retroactive interference, vehicle or drugs were administered subcutaneously (sc) $30 \mathrm{~min}$ before the 1 st sampling session (Figure 1A). For proactive interference, sc administration was performed $30 \mathrm{~min}$ before the 2 nd sampling session (Figure 1B). The testing of the effects of S-CE-123 on proactive vs. retroactive interference was incorporated to get a first insight into the timing and possible interactions of potentially DA signaling for early or late stabilization of an SRM trace.

\section{Microdialysis}

For the preparation of the microdialysis experiment, mice were anesthetized $(5 \mathrm{mg} / \mathrm{kg}$ xylazine, $80 \mathrm{mg} / \mathrm{kg}$ ketamine, i.p., isoflurane) and placed in a stereotaxic frame (David Kopf Instruments, Tujunga, CA, USA). A guide cannula (MAB 4.15.IC, Microbiotech, Stockholm, Sweden; o.d. $0.48 \mathrm{~mm}$ ) was implanted unilaterally $1 \mathrm{~mm}$ above the right nucleus accumbens $(\mathrm{A} / \mathrm{P}=+1.0 \mathrm{~mm}, \mathrm{~L} / \mathrm{M}=+0.8 \mathrm{~mm}, \mathrm{D} / \mathrm{V}=-3.6 \mathrm{~mm})$ according to the mouse brain atlas by Franklin and Paxinos (2007) and fixed to the skull with dental acrylic cement and two stainless steel screws. Animals received buprenorphine ( $5 \mathrm{mg} / \mathrm{kg}, \mathrm{sc}$ ) and an analgesic via the drinking water (Meloxicam, $5 \mathrm{mg} / \mathrm{kg}$, for 3 days) for post-surgery care and were housed individually. The evening before the microdialysis experiment, mice were shortly anesthetized with isoflurane and a microdialysis probe (MAB 4.15.1, Microbiotech, Stockholm, Sweden) with a molecular cutoff of $6 \mathrm{kDa}$ (o.d. $0.2 \mathrm{~mm}$, PES membrane $1 \mathrm{~mm}$ of length) was inserted into the guide cannula of mice reaching into the nucleus accumbens. The probe was connected to a CMA/Microdialysis Syringe pump (CMA-4004) and constantly superfused with sterile artificial cerebrospinal fluid (aCSF; $\mathrm{NaCl}$ $140 \mathrm{mM}, \mathrm{KCl} 3.0 \mathrm{mM}, \mathrm{CaCl}_{2} 1.25 \mathrm{mM}, \mathrm{MgCl}_{2} 1.0 \mathrm{mM}$ and $\mathrm{Na}_{2} \mathrm{HPO}_{4} 1.2 \mathrm{mM}$ and $\mathrm{NaH}_{2} \mathrm{PO}_{4} 0.3 \mathrm{mM}$; pH 7.4) at a flow rate of $0.5 \mu \mathrm{l} / \mathrm{min}$. On the day of experiment, superperfusion rate was set to $1.0 \mu \mathrm{l} / \mathrm{min}$ and after $2 \mathrm{~h}$ of equilibration sequential microdialysis fractions were collected every $20 \mathrm{~min}$ into ice-cooled microtubes containing $6 \mu \mathrm{L}$ of an antioxidative mixture (100 $\mathrm{mM}$ acetic acid, $0.27 \mathrm{mM} \mathrm{Na}_{2}$ EDTA and $12.5 \mu \mathrm{M}$ ascorbic acid), vortexed and stored at $-80^{\circ} \mathrm{C}$ until further analysis. After three baseline samples (collected from -60 to $0 \mathrm{~min}$ ), vehicle or drugs (10 $\mathrm{mg} / \mathrm{kg}$, sc) were administered, and six samples were collected. Subsequently, vehicle or drugs were administered in a higher concentration $(100 \mathrm{mg} / \mathrm{kg}, \mathrm{sc})$ and another six microdialysates were collected. For the last two dialysates aCSF containing $100 \mathrm{mM} \mathrm{KCl}$ was used as a positive control to elicit local depolarization in order to confirm the functionality of the system. At the end of the experiment, mice were euthanized by an overdose of thiopental and brains were removed for histological verification of the placement of microdialysis probes. Data were only used from subjects with correct probe displacement (see Figure 5A).

\section{Analysis of Dopamine}

Dopamine was analyzed in $5 \mu l$ microdialysate fractions by high-performance liquid chromatography (HPLC) with electrochemical detection. The HPLC system consisted of a Shimadzu (Kyoto, Japan) system controller (CBM-20A), degassing unit (DGU-20A3R) and micro HPLC pump (LC20ADXR) operated at a flow rate of $55 \mu \mathrm{l} / \mathrm{min}$. The mobile phase consisted of $8 \%(\mathrm{v} / \mathrm{v})$ methanol, $50 \mathrm{mM}$ phosphoric acid, $50 \mathrm{mM}$ citric acid, $2.36 \mathrm{mM}$ octane-sulfonic acid, $0.1 \mathrm{mM} \mathrm{Na}{ }_{2}$ EDTA at a $\mathrm{pH}$ of 5.6. Samples were injected via a SIL-20ACXR autosampler (Shimadzu, Japan) and separated on a C18 reversedphase column (NeuroSep 105; $50 \mathrm{~mm} \times 1.0 \mathrm{~mm}$ i.d.; $3 \mu \mathrm{M}$ spherical particles; Antec, Zoeterwoude, Netherlands). The HPLC system was coupled to the DECADE II electrochemical detector (Antec SenCell, 2 mm glassy carbon working electrode, $\mathrm{Ag} / \mathrm{AgCl}$ reference electrode, Antec Zoeterwoude, Netherlands). The column and detector cell were maintained at $35^{\circ} \mathrm{C}$ by a column oven as part of the electrochemical detector. The applied potential was set to $+460 \mathrm{mV}$ vs. reference electrode and was adjusted to a detection range of $100 \mathrm{pA} / \mathrm{V}$ with a filter frequency setting of $0.01 \mathrm{~Hz}$. Substance amounts which yielded a detector signal corresponding to three times noise level were considered at detection limit. This allowed for the measurement of DA with a sensitivity of $0.25 \mathrm{fmol} / 5 \mu \mathrm{l}$ sample. Instrument control and data acquisition were carried out by Lab Solution chromatography software (LabSolution CS, Shimadzu, Japan). Calibration curves were constructed in the range of $50 \mathrm{pM}$ to $1 \mathrm{nM}(0.25-5 \mathrm{fmol}$ of DA injected) and were consistently linear with correlation coefficients higher than 0.999 .

\section{Statistics}

Data are presented as mean + SEM. Statistical analysis of the behavioral data was performed by GraphPad Prism 6.05 (GraphPad Software, San Diego, CA, USA). Data obtained from the social discrimination experiments were analyzed using the paired Student's $t$-test. The additional behavioral parameters (latency from the experimental subject to investigate the stimulus animal after its introduction and duration of aggressive behavior) were analyzed using one-way ANOVA. For the microdialysis experiments, the DA content in each 20 min-microdialysate was expressed as a relative value to the mean content rates of the three samples preceding the administration of the drug or vehicle. Statistical analysis was carried out with Statistica Software v9 [StatSoft (Europe) GmbH, Hamburg, Germany] using two-way ANOVA for repeated measures followed by Fisher's test. $P<0.05$ was considered to be statistically significant.

\section{RESULTS}

Investigation durations measured during the 1st and 2nd sampling are presented in Table $\mathbf{1}$. When tested under vehicle conditions, in total two animals (for rac-CE-123 at a $S_{i}=6 \mathrm{~h}$ ) had to be excluded from the analysis of the treatment conditions because the investigation duration during the 1st or 2nd sampling was $<1 \mathrm{~s}$ and, thus, it is unreliable to assume that sufficient information was acquired for a successful recognition and interference, respectively. The data of the remaining animals show that the average investigation duration during both sampling sessions was sufficient to acquire the important 
TABLE 1 | Investigation durations (means + SEM) during the 1st and 2nd sampling of the animals presented in Figures $\mathbf{2 - 4}$

\begin{tabular}{|c|c|c|c|c|c|}
\hline $\begin{array}{l}\text { Corresponding } \\
\text { Figure }\end{array}$ & $\begin{array}{l}S_{i} \text { (type of } \\
\text { interference) }\end{array}$ & Treatment & 1st sampling & 2nd sampling & $n$ \\
\hline \multirow[t]{2}{*}{$2 A$} & 3 h (retroactive) & Vehicle & $23.53+4.59$ & $16.34+3.02$ & 17 \\
\hline & & rac-CE-123 & $26.20+3.34$ & $15.83+4.19$ & 17 \\
\hline \multirow[t]{2}{*}{$2 B$} & $6 \mathrm{~h}$ (retroactive) & Vehicle & $24.02+3.70$ & $14.01+2.73$ & 18 \\
\hline & & rac-CE-123 & $27.09+3.46$ & $15.53+2.07$ & 20 \\
\hline \multirow[t]{2}{*}{$3 A$} & 3 h (retroactive) & Vehicle & $21.41+3.00$ & $17.50+2.70$ & 21 \\
\hline & & S-CE-123 & $27.79+2.56$ & $17.12+2.40$ & 21 \\
\hline \multirow[t]{2}{*}{ 3B } & $6 \mathrm{~h}$ (retroactive) & Vehicle & $26.04+3.82$ & $28.68+4.82$ & 21 \\
\hline & & S-CE-123 & $25.35+4.60$ & $27.30+4.15$ & 21 \\
\hline \multirow[t]{2}{*}{4} & $3 \mathrm{~h}$ (proactive) & Vehicle & $30.78+2.80$ & $30.78+2.80$ & 21 \\
\hline & & S-CE-123 & $34.17+4.50$ & $28.37+4.38$ & 21 \\
\hline
\end{tabular}

It shows the investigation duration of experimental subjects towards presented stimulus animals during the 1 st and 2 nd sampling sessions of retroactive and proactive interference experiments (see Figures 1-4). $n=$ number of animals per group.

information essential to establish long-term SRM and to produce an interference, respectively (Engelmann et al., 2011).

When retroactive interference was introduced at a $S_{i}=3 \mathrm{~h}$, rac-CE-123-, but not vehicle-administered experimental subjects showed significantly longer investigation durations towards the novel stimulus animal than towards the 1st sampled stimulus animal during choice (Figure 2A; paired Student's $t$-test; vehicle: $t=0.73, p=0.475$; drug: $t=4.02, p=0.001$ ). At a $S_{i}$ of $6 \mathrm{~h}$, rac-CE-123-treatment failed to significantly affect the investigation durations during choice (Figure 2B; paired Student's $t$-test: $t=1.81, p=0.087)$. However, vehicle administered experimental subjects investigated the novel stimulus animal significantly longer than the 1st sampled stimulus animal during choice (Figure 2B; paired Student's $t$-test: $t=2.15, p=0.047)$.

Neither administration of S-CE-123 nor that of vehicle caused a significant difference in the investigation of the 1 st sampled and the novel stimulus animal during choice at a $S_{i}=3$ h (Figure 3A; paired Student's $t$-test; vehicle: $t=0.01, p=0.993$; drug: $t=0.21$, $p=0.838$ ). If the same drug was administered at a $S_{i}=6 h$, during the choice session experimental subjects investigated the novel stimulus animal longer than the 1st sampled stimulus animal (Figure 3B; paired Student's $t$-test: $t=2.54, p=0.020$ ). Vehicle treatment failed to affect significantly the investigation durations (paired Student's $t$-test: $t=1.57, p=0.131$ ).

When testing proactive interference and introduced at $S_{i}$ of $3 \mathrm{~h}$, neither vehicle (Figure 4; paired Student's $t$-test: $t=0.96, p=0.348$ ) nor $S$-CE-123 (Figure 4; paired Student's $t$-test: $t=1.11, p=0.279$ ) showed a significant difference in investigation duration between 1st sampled stimulus animal and novel stimulus animal during the choice session.

The data collected from the additional parameters monitored during the behavioral testing are shown in Table 2. Using $\mathrm{S}_{\mathrm{i}}=3 \mathrm{~h}$, no significant effects on any of the additional behavioral parameters monitored were detected (via ANOVA), independently upon the administered substance (vehicle or drug). In contrast, ANOVA statistical test revealed a significant effect on the latency to start investigating the stimulus animal during the 2nd sampling at a $S_{i}=6 \mathrm{~h}$ in case of vehicle treatment only, for rac-CE-123 and its respective vehicle treatment only. Subsequent analysis via Student's $t$-test failed to detect significant differences between the 1 st

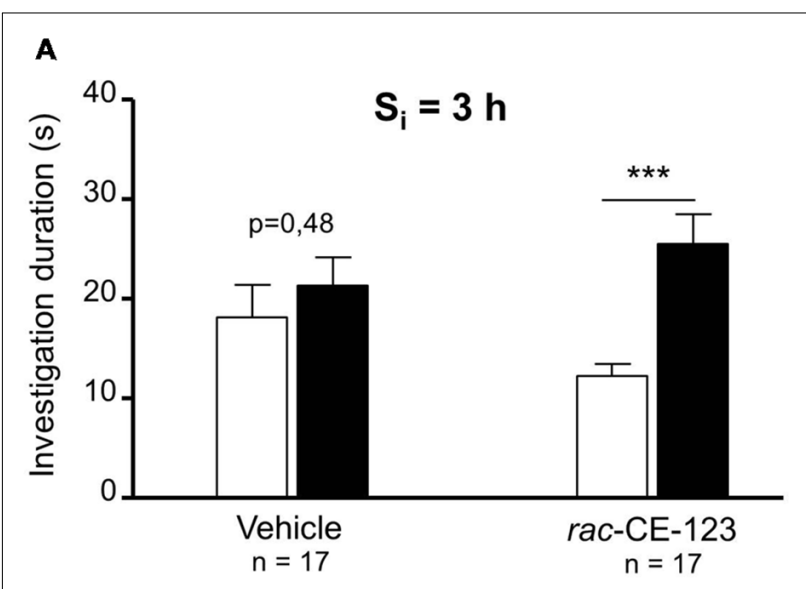

B

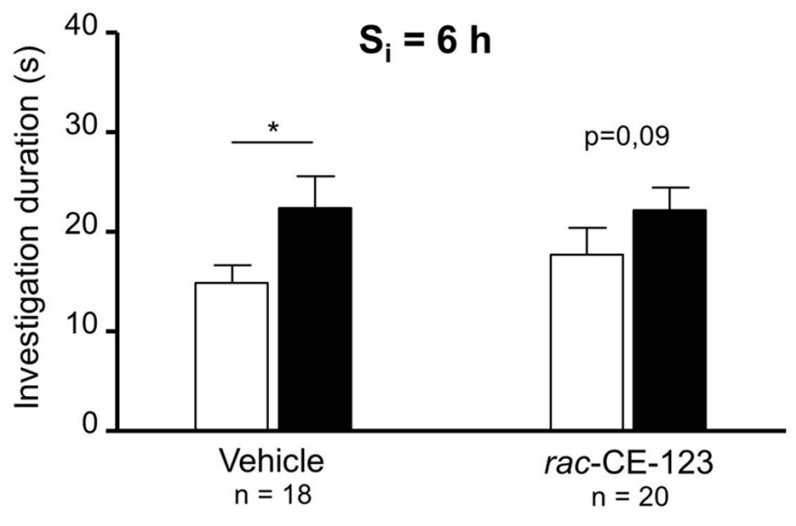

$\square 1^{\text {st }}$ sampled stimulus animal
novel stimulus animal

FIGURE 2 | Effect of subcutaneous injection of vehicle or rac-CE-123 on retroactive interference at $S_{i}=3 \mathrm{~h}(\mathbf{A})$ and $6 \mathrm{~h}(\mathbf{B})$ on social investigation. Recognition memory was tested during choice by exposing the stimulus animal presented during the 1st sampling (1st S) together with a novel stimulus animal mouse $24 \mathrm{~h}$ after the 1 st sampling. ${ }^{*} p<0.05$ and ${ }^{* * *} p<0.01$ paired Student's $t$-test.

and 2nd sampling under a vehicle and the respective drug treatment (data not shown). Thus, the differences detected via ANOVA resulted from different values measured during the 1st 


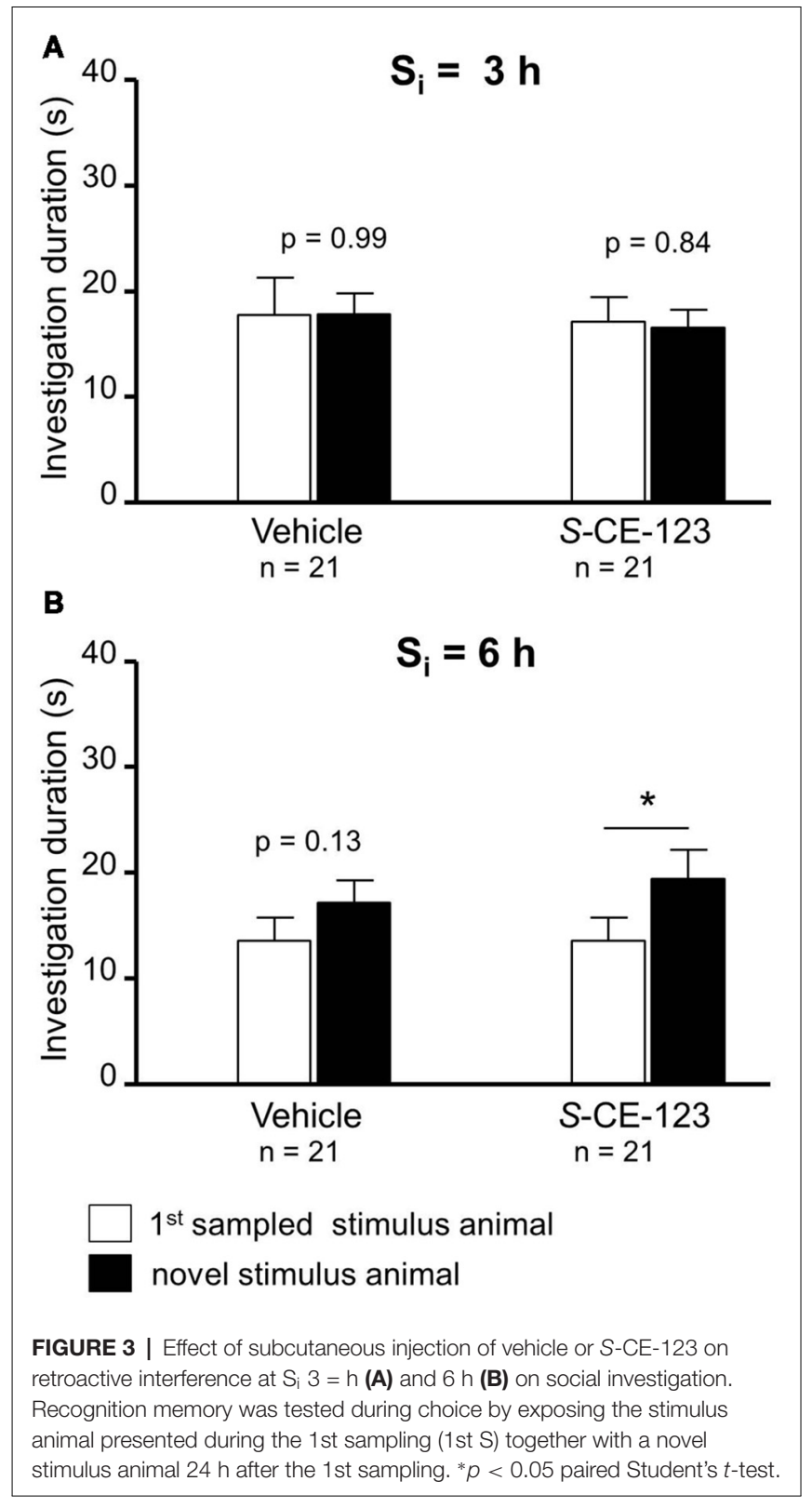

sampling vs. the 2 nd sampling and did not reflect a specific treatment effect.

A representative example of a correct placement of the microdialysis probe in the nucelus accumbens is shown in Figure 5A. DA levels in microdialysates reached stable baseline values of $0.54 \pm 0.08 \mathrm{fmol} / 5 \mu \mathrm{l}$ sample. No significant differences in basal dialysate concentrations of DA between vehicle-treated control group and drug treatment groups were found. Drug treatment significantly affected DA levels over time at both the low (drug $\times$ time interaction: $\left.F_{(16,120)}=1.949, p<0.05\right)$ and high doses (drug $\times$ time interaction: $\left.F_{(16,120)}=11.418, p<0.001\right)$. While vehicle treatment failed to alter the DA concentrations, sc injections of both rac-CE-123 and S-CE-123 increased the concentrations of DA in the microdialysates. Specifically, the administration of $10 \mathrm{mg} / \mathrm{kg}$ of $\mathrm{rac}-\mathrm{CE}-123$ and S-CE-123 caused

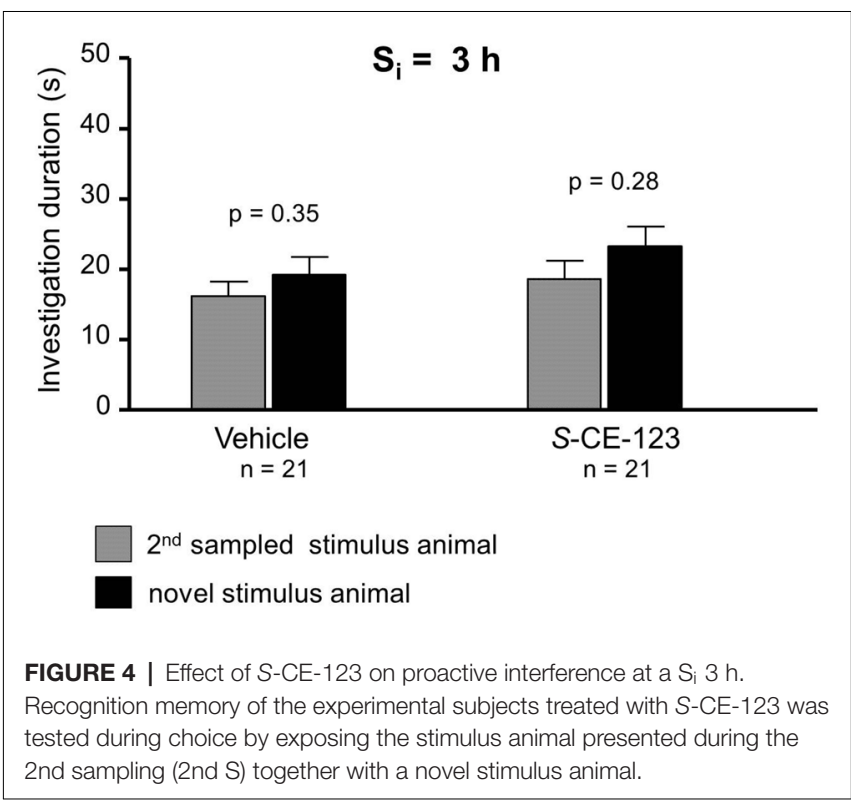

a moderate increase in DA concentrations for at least $20 \mathrm{~min}$ and $40 \mathrm{~min}$, respectively, and returned to baseline levels within the subsequent 40-60 min (Figure 5B). The high dose (100 mg/kg) of both rac-CE-123 and of $S$-CE-123 caused a maximum increase in the DA concentration within $40 \mathrm{~min}(p<0.01)$ after injections and remained elevated throughout the whole sampling period (Figure 5C).

\section{DISCUSSION}

The present study was designed to investigate the impact of recently synthesized and potentially cognitive enhancing drugs on retroactive and proactive interference of SRM. For this purpose, mice injected sc with either rac-CE-123 or S-CE123 were tested in the social discrimination task. Treatment with rac-CE-123 blocked the otherwise seen retroactive interference at $3 \mathrm{~h}$ after the 1 st sampling (Figure 2). However, if the $S_{i}$ between both samplings was $6 \mathrm{~h}$, both drugs failed to affect retroactive interference (Figure 2). Surprisingly, when treated with a vehicle at a $S_{i}=6 \mathrm{~h}$ during the choice session, experimental subjects explored the novel stimulus animal significantly longer than the 1st sampled one (Figure 2B). At first glance, this may indicate that the vehicle treatment has blocked interference. The investigation duration during the 2 nd sampling was similar to the 1st sampling (Table 1) with the ANOVA detecting an increased latency to investigate an increased aggression (Table 2). A similar effect of vehicle treatment on investigation durations during choice, however, is not observed in the other groups tested in the present study (Figures 2, 3) and numberous own unpublished observations with other drugs including modafinil analogues applied under otherwise identical conditions and solvent. Thus, we propose to consider this as an extraordinary outliner, which, nevertheless, will be the focus of further investigations.

With respect to the observed blockage of retroactive interference, administration of rac-CE-123 seems to affect the 
TABLE 2 | Experimental subject's latency to investigate and duration of aggressive behavior (means in seconds + SEM) towards the presented stimulus animal measured during the 1 st and 2 nd sampling, respectively.

\begin{tabular}{|c|c|c|c|c|c|c|}
\hline \multirow[t]{2}{*}{$s_{i}$} & \multirow[t]{2}{*}{ Parameter } & \multicolumn{2}{|c|}{ 1st sampling } & \multicolumn{2}{|c|}{ 2nd sampling } & \multirow[t]{2}{*}{ ANOVA } \\
\hline & & Vehicle & Drug & Vehicle & Drug & \\
\hline \multicolumn{7}{|c|}{ rac-CE-123 (retroactive) } \\
\hline $3 \mathrm{~h}$ & $\begin{array}{l}\text { Latency } \\
\text { Aggression } \\
\text { Latency } \\
\text { Aggression }\end{array}$ & $\begin{array}{l}2.62+0.34 \\
2.05+0.40 \\
3.38+1.16 \\
1.65+0.37\end{array}$ & $\begin{array}{l}3.13+0.55 \\
1.57+0.42 \\
3.85+0.70 \\
3.79+1.25\end{array}$ & $\begin{array}{l}4.47+1.24 \\
2.57+0.73 \\
4.66+0.98 \\
4.81+1.10\end{array}$ & $\begin{array}{l}6.44+1.79 \\
1.90+0.47 \\
2.53+0.49 \\
5.19+1.38\end{array}$ & $\begin{array}{l}F_{(3,80)}=2.25 ; p=0.09 \\
F_{(3,80)}=0.63 ; p=0.63 \\
F_{(3,80)}=1.05 ; p=0.38 \\
F_{(3,80)}=2.10 ; p=0.11\end{array}$ \\
\hline \multicolumn{7}{|c|}{ S-CE-123 (proactive) } \\
\hline $3 \mathrm{~h}$ & $\begin{array}{l}\text { Latency } \\
\text { Aggression }\end{array}$ & $\begin{array}{l}4.05+1.07 \\
2.30+0.72\end{array}$ & $\begin{array}{l}5.03+1.85 \\
1.96+0.54\end{array}$ & $\begin{array}{l}3.48+0.71 \\
4.32+0.69\end{array}$ & $\begin{array}{l}4.60+1.23 \\
4.96+1.13\end{array}$ & $\begin{array}{l}F_{(3,80)}=0.27 ; p=0.84 \\
F_{(3,80)}=2.92 ; p=0.03\end{array}$ \\
\hline
\end{tabular}

Experimental subjects were treated with either rac-CE-123 or S-CE-123 30 min before the 1st sampling (when testing retroactive interference) or the 2nd sampling (when testing proactive interference) and subsequently tested as illustrated in Figures $\mathbf{1 A , B}$. The ANOVA results refer to the values of the sample line.

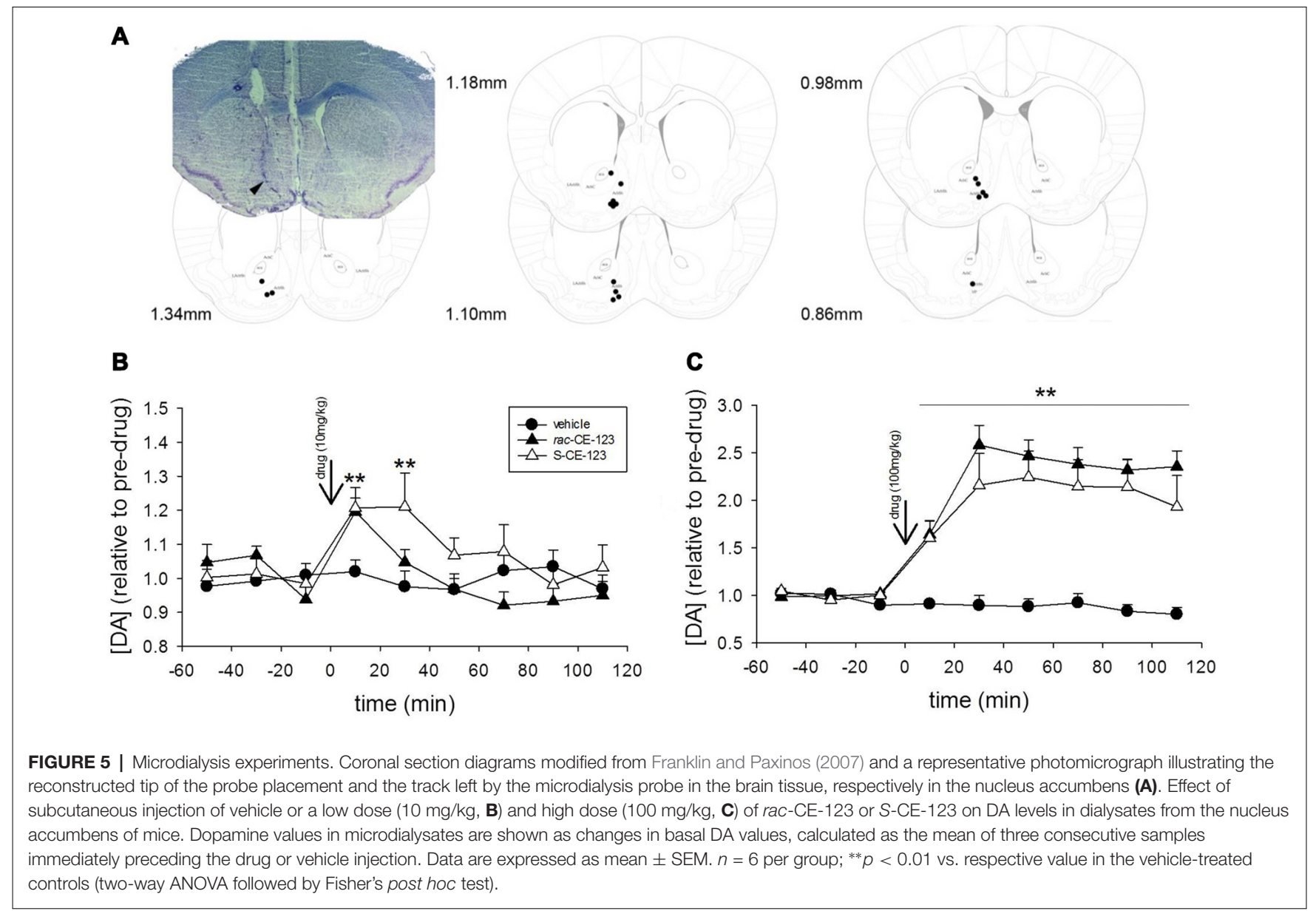

information processing linked to the 1st sampling in a way that it becomes insensitive to a potential interference impact within $<6 \mathrm{~h}$ after learning. It is well known that blocking the DAT activity by psychostimulants prevents the re-uptake of DA and increases the extra-synaptic concentration of DA in the brain (Kuhar et al., 1991; Li et al., 1996). Indeed, our microdialysis experiments revealed a significant increase of extracellular DA levels in dialysates collected from the nucleus 
accumbens after sc administration of both rac-CE-123 and SCE-123. Both drugs increased the DA concentration in the mcirodialysates in a dose- and time-dependent manner. Notably, at the concentration of $10 \mathrm{mg} / \mathrm{kg}$ the maximal response occurred within the first $20 \mathrm{~min}$ followed by a gradual decrease within the next 1-2 h (Figure 5B). The drug-induced release profiles suggest that increased DA levels are to be expected for at least 30-40 min after the sc injection and thus during sampling in the social discrimination task. The data demonstrating a rapid and long-lasting stimulatory effects of novel modafinil analogues rac-CE-123 and S-CE-123 on extracellular DA levels in distinct brain areas including the nucleus accumbens are in line with previous microdialysis studies using modafinil and/or related analogues (Loland et al., 2012; Mereu et al., 2017; Keighron et al., 2019) acting as potential DAT inhibitors. Followed by DAT inhibition, DA D1 receptors seem to be the key mediators in the downstream signaling process (Kalaba et al., 2017) involved in SRM. It is of note that, similar to previous findings, we failed to observe additional effects of the drug treatment on defined behavioral parameters. This speaks in favor of a specific action on memory and not on other behaviorally relevant central nervous processes.

Previous studies have shown that $30 \mathrm{~min}$ after a peripheral injection of rac-CE-123, elevated DAT and DA receptor 1 protein levels in CA1 and CA3 was produced in the hippocampus (Kristofova et al., 2018). Based on these data, it is plausible to state that rac-CE-123 temporarily (i.e., $<6 \mathrm{~h}$ ) protect the memory trace against retroactive interference by manipulating DA signaling in the brain. The action of the drugs cannot easily be explained by an alteration of the general social behavior of the experimental subjects (e.g., reduced interest in the 2nd sampled juvenile or increased aggressive behavior that may have covered reduced investigation) as the behavioral parameters analyzed here failed to differ between vehicle and drug treatment (Table 2). Research studies in rodents revealed that consolidation of long-term SRM is supported by information processing within defined brain areas including the olfactory bulb, anterior olfactory nucleus, medial prefrontal cortex, medial amygdala, basolateral amygdala, and different sub-regions of the hippocampus (Richter et al., 2005; Hitti and Siegelbaum, 2014; Noack et al., 2015; Tanimizu et al., 2017; Lin et al., 2018). Systemic and direct infusion of DA D1 receptor agonists either into the frontal cortex or into the nucleus accumbens improved short-term SRM in rats (Di Cara et al., 2007). Intra-insular cortex administration of agonists for DA D1/D5 receptors, $\beta$ adrenergic and serotonergic $5-\mathrm{HT}_{1 \mathrm{~A}}$ receptors improved the consolidation of SRM in rats (Cavalcante et al., 2017). Further, the potentiation of CA3-CA1 hippocampal synapses facilitates the consolidation of object recognition memory (Clarke et al., 2010). Due to the route of administration used in our study and the analysis of the DA levels in the nucleus accumbens only, we cannot relate the interference blocking effect of the tested drugs to an action within defined brain areas. Inspired by the fact that we could - at least as a potential target-identify the nucleus accumbens, further studies are in progress in which we will analyze the impact of our drugs on distinct areas in which the processing of information for SRM takes place in more detail. Different lines of investigation suggested a contribution of the dopaminergic system in distinct brain regions beyond the nucleus accumbens to the generation of short-term and long-term SRM of laboratory rats. Among them, the hippocampus and striatum are likely to be interesting brain areas (Garrido Zinn et al., 2016; Cavalcante et al., 2017) in which an increased DA signaling might contribute to a "stabilization" of the "SRM trace" and thereby making it resistant against interference.

The enantiomer $S$-CE-123 was able to block retroactive interference at a $S_{i}$ of $6 \mathrm{~h}$ (Figure 3B), but not at a $S_{i}$ of $3 \mathrm{~h}$ (Figure 3A). This indicates that $S$-CE-123 and rac-CE123 administered via the same route and dose may affect differently the dopaminergic signaling relevant for SRM. This could be due to a different profile of washin and washout of the drugs targeting the brain tissue. Unpublished data show that compared to rac-CE-123, S-CE-123 is detectable in a $\sim 5-10$ times higher concentration in both liquor and brain tissue after intraperitoneal administration in adult male rats. The impression of a different duration of action of $S$ - vs. rac-CE123 is - to some aspect-supported by the microdialysis data. The release profile of the racemate at a dosage of $10 \mathrm{mg} / \mathrm{kg}$ differs from that of the $S$-enatiomer by showing elevated DA levels at the sample collected 20-40 min after treatment when rac-CE123 is already indistinguishable from baseline (Figure 5B). In addition, a distinct action of the two drugs on different phases of SRM consolidation might be hypothesized: previous studies demonstrated two separate phases of sensitivity within the first $24 \mathrm{~h}$ after learning in paradigms testing SRM using the protein synthesis blocker anisomycin. This resulted in the hypothesis that the consolidation of long-term SRM requires two stages of protein synthesis with a gap of sensitivity to anisomycin at $\sim 3 \mathrm{~h}$ after learning (Richter et al., 2005; Wanisch et al., 2008). Thus, DA signaling might be involved in the consolidation of SRM at both stages of anisomycin sensitivity. In this context, the effects of $S$-CE-123 differ to that of rac-CE123 in blocking the retroactive interference induced at $3 \mathrm{~h}$ vs. $6 \mathrm{~h}$ after the 1st sampling. Upon first view, this could result from a counter regulatory mechanism of the $S$-enantiomer in the administered racemate. However, such conclusions would be too premature without further studies investigating possible differences in the effects between the two CE-123 treatments including the analysis of molecular mechanisms involved.

The results of the experiment in which we administered S-CE123 in the context with the induction of proactive interference failed to provide a protective effect of this enantiomer for a memory of the 2nd sampled stimulus animals (Figure 4). This speaks in favor of a specific effect of this substance on retroactive, but not proactive interference, and indicates distinct neuronal procedures underlying both phenomena. Previous studies suggested a time-depending interaction of two subsequently initiated memory traces in SRM (Engelmann, 2009), the present data suggest that DA signaling might be involved differently in the generation of retroactive and proactive interference.

Taken together, the results of the present study, show for the first time, that modafinil-derived drugs increasing 
extracellular DA in the nucleus accumbens and acting at both the DAT and DA D1 receptor are able to make SRM resistant against retroactive interference. The drug- and time-dependent action suggests distinct action profiles of the different drugs and provides insight into the mechanisms underlying the consolidation of SRM which requires further investigations. Further studies will focus on the cellular mechanisms via which the modafinil analogues tested here affect SRM. The molecular signatures linked to the blockade of interference are likely to provide further insight into the neurobiological basis of this type of learning and memory in mammals.

\section{AUTHOR CONTRIBUTIONS}

JC-P performed the animal experiments, treated the animals, performed a part of the statistical analysis of the behavioral data and contributed to the manuscript draft. PK was involved in the design and synthesis of the drugs; he also contributed to the design of the study. HV analyzed part of the behavioral

\section{REFERENCES}

Battleday, R. M., and Brem, A. K. (2015). Modafinil for cognitive neuroenhancement in healthy non-sleep-deprived subjects: a systematic review. Eur. Neuropsychopharmacol. 25, 1865-1881. doi: 10.1016/j.euroneuro. 2015.07.028

Camats Perna, J., and Engelmann, M. (2017). Recognizing others: rodent's social memories. Curr. Top. Behav. Neurosci. 30, 25-45. doi: 10.1007/7854 _2015_413

Cavalcante, L. E. S., Zinn, C. G., Schmidt, S. D., Saenger, B. F., Ferreira, F. F., Furini, C. R. G., et al. (2017). Modulation of the storage of social recognition memory by neurotransmitter systems in the insular cortex. Behav. Brain Res. 334, 129-134. doi: 10.1016/j.bbr.2017.07.044

Clarke, J. R., Cammarota, M., Gruart, A., Izquierdo, I., and DelgadoGarcia, J. M. (2010). Plastic modifications induced by object recognition memory processing. Proc. Natl. Acad. Sci. U S A 107, 2652-2657. doi: 10.1073/pnas.0915059107

Dantzer, R., Bluthe, R. M., Koob, G. F., and Le Moal, M. (1987). Modulation of social memory in male rats by neurohypophyseal peptides. Psychopharmacology 91, 363-368. doi: 10.1007/bf00518192

Di Cara, B., Panayi, F., Gobert, A., Dekeyne, A., Sicard, D., De Groote, L., et al. (2007). Activation of DA D1 receptors enhances cholinergic transmission and social cognition: a parallel dialysis and behavioural study in rats. Int. J. Neuropsychopharmacol. 10, 383-399. doi: 10.1017/s1461145706007103

Engelmann, M. (2009). Competition between two memory traces for long-term recognition memory. Neurobiol. Learn. Mem. 91, 58-65. doi: 10.1016/j.nlm. 2008.08.009

Engelmann, M., Hädicke, J., and Noack, J. (2011). Testing declarative memory in laboratory rats and mice using the non-conditioned social discrimination procedure. Nat. Protoc. 6, 1152-1162. doi: 10.1038/nprot.2011.353

Franklin, K. B. J., and Paxinos, G. (2007). The Mouse Brain in Stereotaxic Coordinates. San Diego, CA: Academic Press.

Garrido Zinn, C., Clairis, N., Silva Cavalcante, L. E., Furini, C. R., De Carvalho Myskiw, J., and Izquierdo, I. (2016). Major neurotransmitter systems in dorsal hippocampus and basolateral amygdala control social recognition memory. Proc. Natl. Acad. Sci. U S A 113, E4914-4919. doi: 10.1073/pnas.1609883113

Hitti, F. L., and Siegelbaum, S. A. (2014). The hippocampal CA2 region is essential for social memory. Nature 508, 88-92. doi: 10.1038/nature13028

Kalaba, P., Aher, N. Y., Ilic, M., Dragacevic, V., Wieder, M., Miklosi, A. G., et al. (2017). Heterocyclic analogues of modafinil as novel, atypical DA transporter inhibitors. J. Med. Chem. 60, 9330-9348. doi: 10.1021/acs.jmedchem. $7 \mathrm{~b} 01313$ data and provided the first draft of the manuscript. NA was involved in the synthesis of rac-CE-125, VD in that of S-CE-123. ME designed and supervised the behavioral experiments and contributed to the writing of the manuscript. GL initiated the project and contributed to the study design and to the writing of the manuscript. NS, SS and KE designed and performed the microdialysis experiments including statistical analysis and wrote the draft of the respective parts in the manuscript.

\section{FUNDING}

This study has been partly supported by the Austrian Science Fund (FWF): I2433-B26, SFB F4410 and private funding.

\section{ACKNOWLEDGMENTS}

We wish to thank Rita Murau (Magdeburg) for support in behavioral testing and Dr. Andrew Kaus (Brisbane, QLD, Australia) for polishing the English.

Keighron, J. D., Quarterman, J. C., Cao, J., Demarco, E. M., Coggiano, M. A., Gleaves, A., et al. (2019). Effects of (R)-modafinil and modafinil analogues on DA dynamics assessed by voltammetry and microdialysis in the mouse nucleus accumbens shell. ACS Chem. Neurosci. doi: 10.1021/acschemneuro.8b00340 [Epub ahead of print].

Kristofova, M., Aher, Y. D., Ilic, M., Radoman, B., Kalaba, P., Dragacevic, V., et al. (2018). A daily single dose of a novel modafinil analogue CE-123 improves memory acquisition and memory retrieval. Behav. Brain Res. 343, 83-94. doi: 10.1016/j.bbr.2018.01.032

Kuhar, M. J., Ritz, M. C., and Boja, J. W. (1991). The DA hypothesis of the reinforcing properties of cocaine. Trends Neurosci. 14, 299-302. doi: 10.1016/0166-2236(91)90141-g

Li, M. Y., Yan, Q. S., Coffey, L. L., and Reith, M. E. (1996). Extracellular DA, norepinephrine and serotonin in the nucleus accumbens of freely moving rats during intracerebral dialysis with cocaine and other monoamine uptake blockers. J. Neurochem. 66, 559-568. doi: 10.1046/j.1471-4159.1996.660 20559.x

Lin, Y.-T., Hsieh, T.-Y., Tsai, T.-C., Chen, C.-C., Huang, C.-C., and Hsu, K.-S. (2018). Conditional deletion of hippocampal CA2/CA3a oxytocin receptors impairs the persistence of long-term social recognition memory in mice. J. Neurosci. 38, 1218-1231. doi: 10.1523/JNEUROSCI.1896-17.2017

Loland, C. J., Mereu, M., Okunola, O. M., Cao, J., Prisinzano, T. E., Mazier, S., et al. (2012). R-modafinil (armodafinil): a unique DA uptake inhibitor and potential medication for psychostimulant abuse. Biol. Psychiatry 72, 405-413. doi: 10.1016/j.biopsych.2012.03.022

Mereu, M., Chun, L. E., Prisinzano, T. E., Newman, A. H., Katz, J. L., and Tanda, G. (2017). The unique psychostimulant profile of $( \pm)$-modafinil: investigation of behavioral and neurochemical effects in mice. Eur. J. Neurosci. 45, 167-174. doi: 10.1111/ejn.13376

Müller, G. E., and Pilzecker, A. (1900). "Experimentelle Beiträge zur Lehre vom Gedächtnis," in Zeitschrift für Psychologie und Physiologie der Sinnesorgane EB, $1-300$.

Nikiforuk, A., Kalaba, P., Ilic, M., Korz, V., Dragacevic, V., Wackerlig, J., et al. (2017). A novel DA transporter inhibitor CE-123 improves cognitive flexibility and maintains impulsivity in healthy male rats. Front. Behav. Neurosci. 11:222. doi: 10.3389/fnbeh.2017.00222

Noack, J., Murau, R., and Engelmann, M. (2015). Consequences of temporary inhibition of the medial amygdala on social recognition memory performance in mice. Front. Neurosci. 9:152. doi: 10.3389/fnins.2015.00152

Noack, J., Richter, K., Laube, G., Haghgoo, H. A., Veh, R. W., and Engelmann, M. (2010). Different importance of the volatile and non-volatile fractions of an olfactory signature for individual social recognition in rats versus mice and 
short-term versus long-term memory. Neurobiol. Learn. Mem. 94, 568-575. doi: 10.1016/j.nlm.2010.09.013

Perna, J. C., Wotjak, C. T., Stork, O., and Engelmann, M. (2015). Timing of presentation and nature of stimuli determine retroactive interference with social recognition memory in mice. Physiol. Behav. 143, 10-14. doi: 10.1016/j. physbeh.2015.02.029

Ploeger, G. E., Willemen, A. P., and Cools, A. R. (1991). Role of the nucleus accumbens in social memory in rats. Brain Res. Bull. 26, 23-27. doi: 10.1016/0361-9230(91)90187-O

Richter, K., Wolf, G., and Engelmann, M. (2005). Social recognition memory requires two stages of protein synthesis in mice. Learn. Mem. 12, 407-413. doi: 10.1101/lm.97505

Steckler, T., Drinkenburg, W. H., Sahgal, A., and Aggleton, J. P. (1998). Recognition memory in rats-I. Concepts and classification. Prog. Neurobiol. 54, 289-311.

Tanimizu, T., Kenney, J. W., Okano, E., Kadoma, K., Frankland, P. W., and Kida, S. (2017). Functional connectivity of multiple brain regions required for the consolidation of social recognition memory. J. Neurosci. 37, 4103-4116. doi: 10.1523/jneurosci.3451-16.2017
Thor, D. H., and Holloway, W. R. (1982). Social memory of the male laboratory rat. J. Comp. Physiol. Psychol. 96, 1000-1006. doi: 10.1037/0735-7036.96. 6.1000

Wanisch, K., Wotjak, C. T., and Engelmann, M. (2008). Long-lasting second stage of recognition memory consolidation in mice. Behav. Brain Res. 186, 191-196. doi: 10.1016/j.bbr.2007.08.008

Conflict of Interest Statement: The authors declare that the research was conducted in the absence of any commercial or financial relationships that could be construed as a potential conflict of interest.

Copyright (c) 2019 Camats-Perna, Kalaba, Ebner, Sartori, Vuyyuru, Aher, Dragačević, Singewald, Engelmann and Lubec. This is an open-access article distributed under the terms of the Creative Commons Attribution License (CC BY). The use, distribution or reproduction in other forums is permitted, provided the original author(s) and the copyright owner(s) are credited and that the original publication in this journal is cited, in accordance with accepted academic practice. No use, distribution or reproduction is permitted which does not comply with these terms. 